\title{
Higher Educational Institutions: Efficiency, Competitiveness, Rating
}

\author{
Elena Alexandrovna Kobets
}

\section{Marina Anatolievna Masych}

Southern Federal University, Russia

Email: eakobec@sfedu.ru

\section{Doi:10.5901/mjss.2015.v6n3s4p269}

\begin{abstract}
In the article it is carried out the analysis of indicators of efficiency, competitiveness and ratings of higher educational institutions for the purpose to detect an interdependence and interrelations of these categories and definition of their role in formation of implementation of main mission of Russian leading higher education institutions - joining the leading group of universities of international educational and scientific space. The main directions of formation of competitiveness of the university and offers his concept of "integrated competitiveness." Position of leaders of Russian higher education institutions in international ratings is analyzed, and on the example of Southern federal university its movement trajectory in world and Russian ratings of universities is considered. Thus, substantiates the fact that improving the competitiveness of higher education is the driving force that allows the efficiency and rating of high school to go to a more prominent position in the assessment of their activities.
\end{abstract}

Keywords: efficiency, competitiveness, rating, higher educational institution, federal university;

\section{Introduction}

Competitiveness in this or that quality is present at all types of public work. The essence of determination of competitiveness consists in comparison of the results achieved in relation to similar objects and subjects in questions of activity, production, scientific, personal and other objects and characteristics. The assessment of competitiveness level is carried out by various methods and according to this results its level could be treated as "more-less", "better-worse", "above-below" and other similar phrases (Masych et al., 2014).

Thus, the competitiveness is the dynamic process reflecting condition of object during of certain period of time taking into account external and internal factors in comparison with similar organizations.

\section{Higher Education Institutions Competitiveness}

Competitiveness of higher educational institutions depends on many factors (Kobets et al., 2010). The major of them, according to the Ministry of Education and Science of the Russian Federation are: an educational activity - the Unified State Examination point, research work - research and development volume counting on one scientific and pedagogical worker (SPW), international activity - a specific weight of being trained foreign students, financial and economic activity the higher education institution income from all sources counting on one SPW and infrastructure, i.e. the total area of educational - laboratorial buildings counting on one student (Government of Russia, 2012). Taking into account these criteria using a special methodic the Ministry determines a level of efficiency of higher education institution and in comparison with other similar higher education institutions it is possible to judge the competitiveness level between them.

But the sense of competitiveness lies much deeper than the provided list of indicators. Thus some indicators, for example a number of being trained foreign students, for the majority of higher education institutions of Russia are lowreal.

Michael Porter notes that the «competitiveness is conditioned rather by efficiency with what the firms on places are using the facility for production of goods and services» (Porter, 2001).

Refracting this statement for criteria inducted by the Ministry of Education and Science and carrying out a monitoring of higher education institutions efficiency, it is possible to identify quite reasonably the concept efficiency of higher education institution - competitiveness of higher education institution (Government of Russia, 2013). At the same time it should be noted that if efficiency of higher education institution is defined by five criteria, then the competitiveness 
of higher education institution it is the wider concept which has absorbed in the essence a set of indicators. Nevertheless, it is possible to consider the efficiency of higher education institution as the integrated cut of its competitiveness, and the estimates per research and financial and economic indicators of activity are the markers of exit to the Russian and international rating level.

\section{Integrated Competitiveness of Higher Education Institutions}

Let's consider the main directions of higher education institution competitiveness formation. The parameters of entrance competitiveness of higher education institution is accepted the average point of USE Unified State Examination for school level, the volumes of scientific and technical development offered for implementation, the competition level on positions replacement of scientific and pedagogical workers, the number of invitations for participation of employees in the AllRussia and international scientific and educational conferences and symposiums, the number of foreign students, desired to study at given university, the number of foreign teachers and scientists participating in educational and scientific process, brand, prestige of higher education institution and so on (Kobets et al., 2010).

To output parameters of higher education institution competitiveness relate: the demand of employers of higher education institution graduates per target factor and independent job search on specialty. The employers' references on professional level of workers earlier graduated in higher education institution, the actually achieved scientific and financial results at performance of scientific and technical development, the scientific articles citation index, articles for international publishing houses, the graduates' references on quality of training in higher education institution and others.

Entrance and output competitiveness is connected to the internal competitiveness. It is possible to carry to parameters of internal competitiveness the condition of material and technical basis and higher education institution infrastructure, the level of workers salary, the condition of methodical base of students training and its compliance to requests of the market, the qualification of scientific and pedagogical employees of higher education institution, the progressiveness of organizational structure of governing and efficiency of management at all its levels, the social security of workers and so on.

External competitiveness of higher education institution can be characterized by such parameters as competition among similar higher educational institutions, influence of federal, regional and municipal policy in education field, communications with employers of graduates and customers of scientific and technical development, financing arrangements by the state and private business for higher education institution activity, communication with scientific educational and methodical institutional structures in Russia and abroad.

Thus, the competitiveness of higher educational institutions develops of four components: entrance competitiveness, internal competitiveness, output competitiveness, external competitiveness. Having united all these types of competitiveness into whole it is possible to apply the concept of integrated competitiveness which gradient aims at exit to the Russian and international ratings of higher educational institutions (fig. 1).

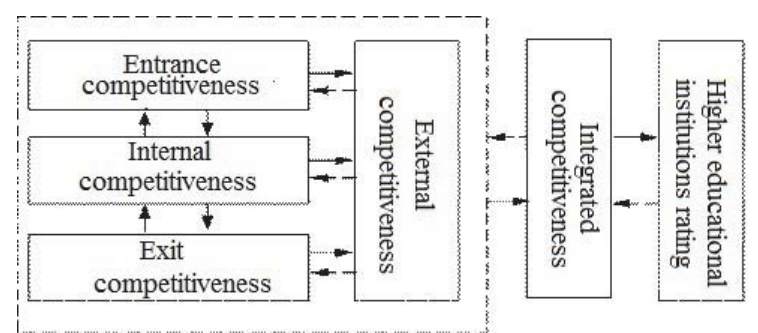

Fig.1. Integrated competitiveness of higher education institutions.

The parameters of all of competitiveness types mutually dependent on each other both: directly, and indirectly. For example, the salary of scientific and pedagogical workers influences the level of entrance competitiveness and if it is worthy, it promotes an attraction of more qualified personnel and vice versa.

\section{The Position of Higher Education Institutions - The Leaders in Russia in International Ratings}

The Russian leading higher education institutions' mission for last years' happens to be the entrance into Russian world ratings reflecting the success of their activity (Petrosyants and Tchaplygin, 2014). These higher education institutions are passing to the international criteria of activity assessment due to connection with transition to dual-level education system, with the number of scientific articles of employees for foreign magazines, with index of citing, share of foreign teachers and students and with some other indicators. 
In the Decree «About measures for realization of the state policy in the fields of education and science», signed by President V. V. Putin of 07 May, 2012 it is a task to provide an occurrence by year 2020 not less than 5 Russian universities into the first hundred leading world universities list according to global world ratings (Putin, 2012).

The plan of measures has been worked out on increasement of leading universities competitiveness and occurrence in the first hundred in one of three global ratings THE WORLD UNIVERSITY: the world rating of universities (THE), the academic rating of universities of the world (ARWU), or rating of best universities of the world (QS). Financing has been for this purpose planned from the state side in the volume of 35 billion rubles and an open competition was announced in which 54 Russian higher education institutions have provided the programs. Per results of assessment by the special commission the 15 higher education institutions have been selected, leaning on their today's condition and potential abilities. Unfortunately, by results of year 2012 only the Moscow State University and the St. Petersburg State University have hit the list of 400 best higher education institutions according to version THE, and in year 2013 in this category there was only Moscow State University. In year 2012 of MEPhl has appeared in rather prestigious interval (226-250 place) which is the best result of this higher education institution. Thus on separate indicators of rating these higher education institutions occupy higher places. For example, in TNE rating in year 2012 the highest grade 100 indicator of MEPhl reaches owing to two scientific articles with all time citation indexes (3306 and 4916). But on quoting in summary rating it is possible to gather at most 30 points from 100, and the backlog per other criteria didn't allow to MEPhl to hit higher position in the general rating(Arefyev, 2014). The general rating on TNE in year 2013 was the highest at the Californian Institute of technology - 94, 9 points. Ranging of higher education institutions on global ratings (THE, ARWU, QS) as a whole is based on similar indicators, such as training and training environment, research-volume-incomeresults, quoting index, income from scientific production activity, international image, winners of the Nobel and Fildsov awards who have graduated from this educational institution or working in there and some others (Arefyev and Moshnyaga, 2014).

In QS rating the basis is an expert polling in scientific environment on which it is possible to receive $40 \%$ of points, polling of employers - $10 \%$, ratio of students and faculty - $20 \%$, number of quoted articles per one scientific and pedagogical worker - $20 \%$, share of foreign students - $5 \%$, share of foreign scientific and pedagogical workers of $5 \%$. The Russian higher education institutions participate in this rating. Thus the Moscow State University in year 2013 has taken the 120th place and has gathered 63, 9 points, the St. Petersburg state university 240th place with about 45, 9 points. On the first place the Massachusetts Institute of Technology with 100 points. The first hundred obturate the universities which have gathered from 68 to 70 points. From this it is visible that the greatest competition for entry into the first hundred higher education institutions is in these limits (Arefyev, 2014).

In the Shanghai rating (ARWU) which is also the global rating, there are no indicators on number of students, teachers and financial results. The main role is played by only scientific activity and existence at employees - graduates from higher education institution of awards of Nobel and Filds. In ARWU rating by special technique it is estimated the quality of training, quality of the faculty, scientific productivity per one worker. Thus the scientific articles published in Nature and Science magazines give the main value. The Russian higher education institutions in this rating are unobtrusive. The Moscow State University of Lomonosov since 2001 till 2005 has hit the first hundred digit group of universities, and the St. Petersburg State University has taken the places from 301 till 400. The Voronezh and Novosibirsk State universities, the Kazan and Ural federal universities have got rather appreciable points on separate indicators of rating (Arefyev, 2014).

Quite successfully the Russian higher education institutions participate in the international rating of WEBOMETRICS universities at the heart of which it is ground the growth of online publications, communication expansion between the scientists and teachers, formation of new communications, efficiency, simplicity and profitability of information volumes (Karpenko and Bershadskaya, 2014). This rating characterizes the network component of higher education institutions (Gusev and Novikova, 2014). In rating more than 12000 universities of the world are ranged.

Indicators of rating are the quantity of web pages which give $20 \%$ of points, number of external references on site from Majestic SEO and Ahrefs (50\%), number of saturated files (15\%), the indicator considering the scientific articles in authoritative international magazines (15\%). The Russian higher education institutions in last six ratings (2007-2013 y.y.) are included into the first ten the countries (Gusev and Novikova, 2014). The regional federal universities dominate among the best Russian higher education institutions, this confirm an efficiency of such schoolings creation, but insufficient quality of scientific researches scotches Russia in this rating of advancing to higher places.

Having considered the movement of Russian higher education institutions in the most significant world ratings it is possible to ascertain the positive tendency consisting in the inclusion of higher education institutions into international system of quality assessment of education and scientific researches (Birnbaum, 2014). The more increasing number of higher educational institutions issues the challenge before themselves on participation in various ratings. But thus the 
success of participation in this or that rating should depend on the weighed approach to assessment of current component of scientific and pedagogical activity, potential of development and prospects of objectives implementation. The short analysis of statistical information on points quantum gathered on various indicators in ratings for the last 2 years, can serve as reference point for university from the point of view of participation in this or that rating. As a rule, the universities accept a participation in several ratings and can achieve good result as a whole on rating, and on its separate indicators (Khodyrev, 2014).

In recent years there were new international ratings, such as rating of universities of $\mathrm{CIS}$ countries, rating of universities of former Soviet Union countries, TNE rating of higher education institutions of BRIKS countries and of countries with the rising economy, new rating of higher education institutions of BRIKS countries according to QS version, the international rating of young higher education institutions, and also internally ratings of various countries. At the heart of these ratings are put both criteria of leading international ratings, and new indicators.

\section{Trajectory of Movement of the Southern Federal University in Ratings}

On the example of the Southern federal university (FSAI) we will consider its trajectory of movement in world and Russian ratings of universities. The Russian academic rating is estimated in 2010-2013 by five criteria which define level of efficiency of higher educational institutions. It is thus supposed that the higher education institutions which have got in TOP-100 appear in the sphere of fixed interest of consumers, the authorities and business. The generalized rating on the basis of calculations of factors of activity and stability gives the first three places to the higher school of economy (100 points), the Moscow State University (83 points), MGIMO (76,5 points). The southern federal university the first of federal universities has taken honorable 11th place, having gathered 38,5 points. Following the results of 2012 of FSAl has taken the 867th place in the international rating of WEBOMETRICS instead of planned 600. It was the first real test of level of competitiveness in the international ratings. The rating of WEBOMETRICS is included into number of leading ratings, analyzing not educational activity of university as a whole, and representation of higher education institution in Internet space. The rating allows estimating indirect way research activity of higher education institution through comparison of Internet sites. FSAI possesses the powerful diversified scientific base, allowing mastering considerable volumes of research and development. The scientific potential of scientific and pedagogical workers dynamically grows that is positively reflected in productivity of scientific achievements. In this rating more than 12000 best educational institutions of the world and the 867th place - quite good result are ranged, considering that it in essence the first showdown.

Following the results of 2013 of FSAl has shown high-quality break, having accepted fate in rating of the best universities of the world (QS) having taken position in cluster 601-650, thereby has confirmed the joining to group of dynamically developing universities of the world (Borovskaya, 2013). Among 15 Russian higher education institutions participating in this rating of FSAI has taken the 14th place. In world rating of WEBOMETRICS for January, 2013 of FSAI has taken the 999th place in the world and the 12th place among the Russian universities. As of August, 20131351 places and the 10th place in Russia respectively.

Improvement of positions at rating level in comparison with year 2012 specifies probably the growth of information volume on university web pages with simultaneous accretion, of indicators of scientific activity.

In Russian ratings the position of FSAI are quite successful. So in national rating of INTERFAX agency among 105 Russian higher education institutions following the results of 2012, FSAI has taken the 12th place, and on indicator «research activity» the 3rd place. In rating of higher education institutions of Russia according to the Expert RA rating agency version per criterion «research activity» the higher education institution has taken the 6th place among 100 of Russian universities and the 24th place in summary rating of year 2013 (Borovskaya, 2012). Analyzing the FSAI achievements in ratings of year 2013 in comparison with 2012, it should be noted an appreciable increase of competitiveness of university both: in international, and in Russian space. The results shown characterize the high level of FSAI competitiveness among the Russian higher education institutions.

For more productive advance of FSAl in new international authoritative ratings it is necessary to increase the tendencies of main criteria of indicators which are considered on them. As FSAI possesses a powerful scientific base (rather large scientific research institutes, experimental design bureau, laboratories, scientific and technological centers, etc.) and also an effective scientific activity of departments, in our opinion, it is necessary to emphasize such ratings in which the greatest number of points can be received for scientific development, researches, scientific articles, citing index. It is necessary to increase a number of scientific articles and reports in English, published on sites of university and in magazines. Thus the other criteria considered in ratings, shall be improved and developed continuously that will promote an advance in summary rating.

Thus, having considered an essence of efficiency of higher education institutions, competitiveness and rating it is 
possible to note their close interrelation and interdependence that, in fact, characterizes a competitive position of higher education institutions in the sphere of their activity. Competitiveness is the base of development of higher education institutions efficiency and positioning in Russian and international ratings. Formally the concepts efficiency, competitiveness, rating reflect a quantitative assessment of ranging and a place which was occupied by higher education institution for the current period in comparison with previous. At the same time the competitiveness includes the bigger number of indicators and criteria, than the efficiency of higher education institutions and ratings. As a whole an increase of competitiveness of higher education institutions presents that dynamics which allow to efficiency and rating of higher education institution to chalk up on higher positions at assessment of their activity.

The outcomes of investigations, stated in this article, are gained with financial support of the Ministry of Education and Science of the Russian Federation within the project implementation "Creation of hi-tech production on manufacture of portable multipurpose hardware-software complex of long-term cardio-monitoring and ergometry" under the Resolution of the government No. 218 of 4/9/2010. The investigations were carried out in FSAEI HPE SFU (SFedU).

\section{References}

Putin, V.V. (2012). The decree of the President of Russian Federation V. V. About measures for implementation of State policy in the fields of education and sciences No. 599

The Government of Russian Federation. (2012). The order about the approval of measures plan on development of the leading universities providing an increase of their competitiveness among the leading world scientific and educational centers No. 2006-R.

The Government of Russian Federation. (2013). The order about the statement of council structure on increase of competitiveness of leading universities of the Russian Federation among the leading world scientific and educational centers No. 529-R.

Arefyev, P. A. (2014). Rating THE of higher education institutions of BRIKS countries and countries with rising economy. Digest. Measurement of universities ratings: an international and Russian experience / under the editorship of F.E.Sherega and A.L.Arefyev/Ministry of the Russian Federation education and sciences. Moscow. Center of sociological researches.

Arefyev, A.L. (2014). Russia in the international market of education. Digest. Measurement of universities ratings: an international and Russian experience / under the editorship of F.E.Sherega and A.L.Arefyev / Ministry of the Russian Federation education and sciences. Moscow. Center of sociological researches.

Arefyev, A.L., \& Moshnyaga, V.P. (2014). International rating of young higher education institutions. Measurement of universities ratings: an international and Russian experience / under the editorship of F.E.Sherega and A.L.Arefyev/ Ministry of the Russian Federation education and sciences. Moscow. Center of sociological researches.

Arefyev, P. A. (2014). International ratings of higher educational institutions: history and modern situation. Measurement of universities ratings: an international and Russian experience / under the editorship of F.E.Sherega and A.L.Arefyev/ Ministry of the Russian Federation education and sciences. Moscow. Center of sociological researches.

Borovskaya, M. A. (2012). The annual report on FSAl activity for year 2012. Rostov-on-Don.

Borovskaya, M. A. (2013). The annual report on FSAl activity for year 2013. Rostov-on-Don.

Gusev, I.A., \& Novikova, O.S. (2014). New rating of higher education institutions of BRIKS countries according to QS version. Measurement of universities ratings: an international and Russian experience / under the editorship of F.E.Sherega and A.L.Arefyev/Ministry of the Russian Federation education and sciences. Moscow. Center of sociological researches.

Karpenko, O. M., \& Bershadskaya M. International rating of WEBOMERTRICS universities: the dynamics of network activity of Russian higher education institutions (2007-2013). Measurement of universities ratings: an international and Russian experience / under the editorship of F.E.Sherega and A.L.Arefyev / Ministry of the Russian Federation education and sciences. Moscow. Center of sociological researches.

Kobets, E.A., Makarenya, T.A., Nalesnaya, Ya.A., Egorov, A. V, Kazanskaya, A.Yu., \& Korsakov, M. N. (2010). Ways of improvement and modernization of educational activity of the Southern federal university. Moscow. International magazine of experimental education.No. 12.

Kobets, E.A., Makarenya, T.A., Nalesnaya, Ya.A., Egorov, A. V, Kazanskaya, A.Yu., \& Korsakov, M. N. (2010). Ways of improvement and modernization of educational activity of the Southern federal university (monograph). Moscow. Publishing house High school book.

Masych, M.A., Kobets, E.A., \& Kaplyuk, E.V. (2014). The effective contract in system of university teachers stimulation. SGEM Social\&Arts, Bulgaria, 597-604.

Petrosyants, D. V., \& Tchaplygin, A.G. (2014). Rating of leading universities of the former Soviet Union as tool of assessment of national educational systems. Measurement of universities ratings: an international and Russian experience / under the editorship of F.E.Sherega and A.L.Arefyev / Ministry of the Russian Federation education and sciences. Moscow. Center of sociological researches.

Porter, M. (2001). Competition. translated from English. The manual. Moscow. Publishing house William.

Birnbaum, R. (2014). New methods of universities ranging Measurement of universities ratings: the international and Russian experience I Under the editorship of F.E.Sherega and A.L.Arefyev/ Ministry of the Russian Federation education and sciences. Moscow. Center of sociological researches.

Khodyrev, A.A. (2014). Preparation of new rating of universities of CIS. Measurement of universities ratings: an international and Russian experience / Under the editorship of F.E.Sherega and A.L.Arefyev/ ministry of the Russian Federation education and sciences. Moscow. Center of sociological researches. 